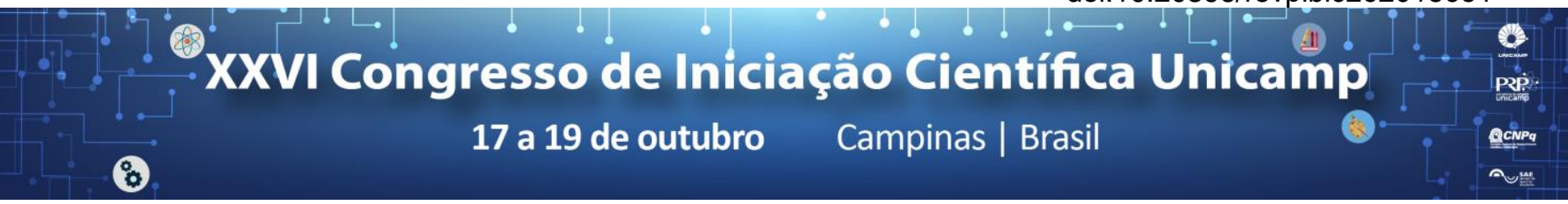

\title{
Ganho Óptico em Nanomateriais de Perovskita
}

\section{Jaqueline Rocha*, Gabriel Nagamine, Luis G. Bonato, Lázaro A. Padilha, Carlos H. de Brito Cruz}

\section{Resumo}

Observamos que em pontos quânticos de Perovskita $\mathrm{CsPbBr} 3$ excitados por absorção de 2 fótons há uma forte dependência entre o tamanho do ponto quântico e o limiar de amplificação da emissão espontânea, mostrando um limiar de ganho óptico tão baixo quanto $1,6 \mathrm{~mJ} / \mathrm{cm}^{2}$ sob excitação de $1,55 \mathrm{eV}$.

\section{Palavras-chave: Perovskite Quantum Dot, Absorção de 2 Fótons, Amplificação da Emissão Estimulada}

\section{Introdução}

Os Pontos Quânticos de Perovskita $\mathrm{CsPbBr}_{3}$ (PQD, do inglês Perovskite Quantum Dots) surgiram como uma nova classe de nanomateriais promissora para aplicações em dispositivos, incluindo lasers e LEDs $^{1}$ devido às suas excelentes propriedades optoeletrônicas.

Neste trabalho, estudamos os métodos de síntese desses nanomateriais e investigamos a dependência do ganho óptico por absorção de 2 fótons em PQDs e sua seção de choque para entender tais propriedades.

\section{Resultados e Discussão}

Usamos um sistema composto de um laser Ti:safira, operando em 800nm e com pulsos de 80fs, para excitar pontos quânticos de Perovskita de diversos tamanhos dispostos em filmes finos. Para gerar a amplificação da emissão espontânea (ASE) por absorção de 2 fótons (2PA), excitamos o filme com uma lente cilíndrica e detectamos o sinal com uma objetiva na lateral do filme.

Conforme aumentamos a potência de excitação, é possível observar o aparecimento de um estreito pico de emissão, indicando o ASE.

O pico de ASE, mostrado na Figura 1, está desviado para o vermelho em relação ao pico de fotoluminescência, indicando que é originado da emissão do biéxciton.

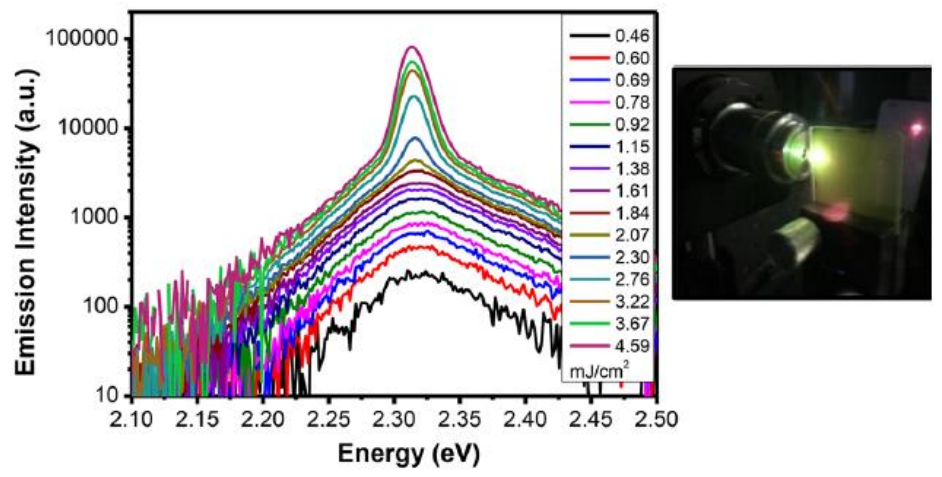

Figura 1. À esquerda, espectro de emissão em função da intensidade do pulso de excitação a $1.55 \mathrm{eV}$ para PQD sintetizado a $75^{\circ} \mathrm{C}$. À direita, foto da montagem experimental.

Como mostramos no artigo resultante deste projeto ${ }^{2}$, verificamos que as nanopartículas de Perovskita possuem grande seção de choque de absorção de dois fótons (cerca de $10^{6} \mathrm{GM}$ ), a qual cresce linearmente com o volume da partícula. Considerando essa seção de choque, calculamos o limiar de ganho óptico em função do número médio de éxcitons por $P Q D$, como mostrado na Figura 2, excitando $\mathrm{PQDs} \mathrm{CsPbBr}_{3}$ de tamanhos variados $(7,4$ a $12,5 \mathrm{~nm})$ por $2 \mathrm{PA}$. Observamos que 0 limiar de ganho diminui conforme diminuímos o tamanho da nanopartícula, indicando clara dependência com suas dimensões.

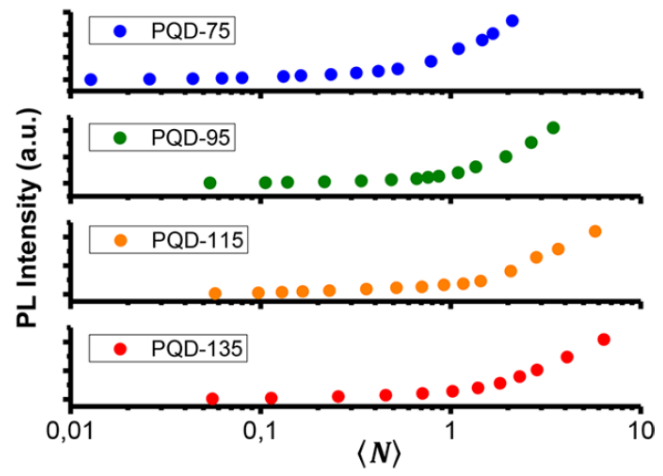

Figura 2. Espectro de emissão em função do número médio de éxcitons por quantum dot para 4 amostras de tamanhos diferentes. O limiar de ASE é o ponto onde a curva cresce drasticamente.

\section{Conclusões}

Os resultados aqui apresentados e que foram publicados na Ref. 2, pela primeira vez esclarecem a origem física das propriedades relacionadas ao baixo limiar de ganho óptico por absorção de 2 fótons em PQDs. Observamos que a energia de ligação do biéxciton é diretamente dependente do tamanho dos PQDs, o que indica que o desvio para o vermelho causado pela energia do biéxciton reduz a reabsorção favorecendo a amplificação da emissão espontânea.

\section{Agradecimentos}

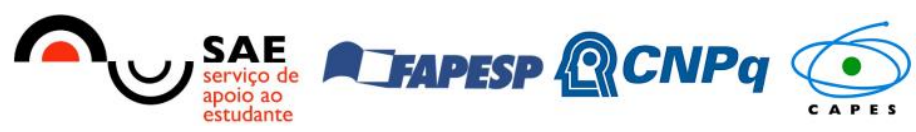

1 Yassitepe, E.; Yang, Z.; Voznyy, O.; Kim, Y.; Walters, G.; Castañeda, J. A.; Kanjanaboos, P.; Yuan, M.; Gong, X.; Fan, F.; et al,. Adv. Funct. Mater. 2016, 26, 8757-8763.

${ }^{2}$ Nagamine, G., Rocha, J. O., Bonato, L. G., Nogueira, A. F., Zaharieva, Z. Watt, A. A. R. e Padilha, L. A., J. Phys. Chem. Lett., 2018, 9 (12), 3478-3484 